\title{
Experimental Determination of the Kinetic Rate Law for the Oxidation of Acetone in Aqueous Environment by Potassium Permanganate and Sulfuric Acid at $25^{\circ} \mathrm{C}$ and Proposed Mechanism for the Reaction
}

\section{SAYYED HOSSEIN RASA ${ }^{1 *}$ and MOHAMMAD-TAHA BADRI ${ }^{1}$}

\author{
${ }^{1}$ Thermodynamic Research Laboratory, Department of Physical Chemistry, Faculty of Chemistry, \\ University of Kashan, Kashan, Iran. \\ *Corresponding author E-mail: Rasa@Kashanu.ac.ir
}

http://dx.doi.org/10.13005/ojc/350142

(Received: October 16, 2018; Accepted: December 05, 2018)

\begin{abstract}
This research paper aims to determine of the rate equation for the reaction that is described in this article.Experiments carried out by using iodometric method for determine the concentration of potassium permanganate at different times. The results are very similar to the results of the UV-Visible spectrophotometric method. These results showed that order of reaction for acetone, potassium permanganate and sulfuric acid were 1,1 and 1, respectively. Therefore, the rate equation is according to the chemical equation. In addition, it was demonstrated that there was no relationship between products concentration and rate of reaction. A suitable mechanism is also suggested. Thus, the reaction rate law implies a complicated reaction mechanism with low acetone concentrations. In addition, elevated temperature and reactants concentrations are required for a fast acetone oxidation. A reaction mechanism in good consistent with the kinetic results will be suggested and discussed.
\end{abstract}

Keywords: Rate equation, Potassium permanganate, Lodometric method, Spectrophotometric method, Mechanism.

\section{INTRODUCTION}

Acetone is a clear, colorless, volatile and flammable liquid with a characteristic odor described as pungent or fruity. It is primarily used as an industrial solvent and chemical intermediate. Acetone is also found in paints, varnishes and lacquers and is used as a solvent for cements in the leather and rubber industries. Because acetone does not adsorb to soil strongly and is highly water soluble, acetone-containing wastes released to soil will tend to leach to groundwater. The odor threshold for acetone in water is reported to be 20 parts per million (ppm); the reported odor threshold in air is in the range of 13 to $20 \mathrm{ppm}$. Acetone is a natural metabolism product of both plants and animals, including humans. Those who fast, consume a high fat, low carbohydrate diet and do exercise strenuously have uncontrolled diabetes and are likely to produce higher than usual levels. Acetone is quickly absorbed

This is an Open Access article licensed under a Creative Commons license: Attribution 4.0 International (CC- BY). Published by Oriental Scientific Publishing Company @ 2018

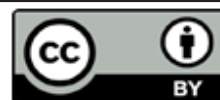


by ingestion, inhalation, and dermal exposure. In two experiments with humans, inhalation absorption was in the 70 to 80 percent range. There is no data for the other routes. Absorbed acetone is almost entirely eliminated from the body within a day after exposure. Mild nervous system effects such as eye and respiratory irritation, mood swings, and nausea that abated soon after exposure ended were seen in humans breathing high concentrations of acetone. Accidental poisonings report similar nervous system effects of sluggishness and drowsiness that were not long lasting. There is only one animal study that investigated the effects of acetone exposure by ingestion. Rats were given drinking water containing acetone for 18 weeks. The only effect observed in the rats was weight loss, which may be attributed to decreased food consumption. Humans exposed to high levels of acetone by inhalation experienced eye and nasal irritation. Exposure to somewhat lower concentrations did not cause any adverse health effects. In another study, groups of students were exposed by inhalation to acetone for six hours. At the higher concentrations, eye, nose and throat irritation were observed. Workers exposed by inhalation to acetone for three hours per day for seven to 15 years complained of respiratory tract irritation, dizziness, and loss of strength. In animals exposed to very high doses of acetone in drinking water, effects on the blood indicating an anemic condition were reported. Male rats exposed to very high concentrations of acetone in drinking water had increases in malformed sperm and reduced sperm movement. Whether these effects would impair reproductive ability is not known ${ }^{1-9}$. Potassium permanganate is selected as an oxidizing agent for our present study because; it is an economically low cost material. It has high oxidation potential $\left[\mathrm{E}^{0}=1.51 \mathrm{~V}\right]$, it can oxidize wide variety of substances and it is effective over wide range of $\mathrm{pH}$. There are various oxidation states of Mn like (+II, + III, +IV, +V, $+\mathrm{VI}$ and $+\mathrm{VII})$. Hence, it become very complicated to find out the exact species involved in it. ${ }^{10}$

Recently, environmental problems persuaded researchers to pay attention to acetone oxidation in gaseous and aqueous media for optimizing the process. In the gaseous medium the process has been proceeded in presence of different catalysts such as platinum, palladium and oxides of chromium, cobalt, copper, nickel and manganese. The transition metals have been supported on different metal oxides such as $\mathrm{Al}_{2} \mathrm{O}_{3}, \mathrm{MgO}$ and $\mathrm{ZrO}_{2}$ supports. ${ }^{11-14}$ In liquid medium, oxidation of organic compounds in presence of potassium permanganate has been investigated widely. Aqueous acetone oxidation also has been performed in presence of potassium permanganate with different conditions. Our extensive studies in dealing with acetone environmental remediation acetone has resulted in the use of potassium permanganate as its oxidation agent. In the present paper we report our kinetics studies of potassium permanganate oxidation of acetone. Our extensive research indicated that the reaction rate law for this process is: Reaction Rate Law $=\mathrm{k}\left[\left(\mathrm{CH}_{3}\right)_{2} \mathrm{CO}\right]^{1}\left[\mathrm{KMnO}_{4}\right]^{1}\left[\mathrm{H}_{2} \mathrm{SO}_{4}\right]^{1}$ $\left[\mathrm{MnSO}_{4}\right]^{0}\left[\mathrm{CH}_{3} \mathrm{CHOOH}\right]^{0}[\mathrm{HCOOH}]^{0}$ and related data for reactant concentrations versus time extracted and diagrams of [reactant] ${ }^{-1}$, and $\operatorname{In}$ [reactant] versus time were plotted with the hope that a linear relationship to be found. ${ }^{15-24}$ The reaction rate law is significant information that has an important role to understand the mechanism. Reaction kinetics determines the best way to achieve desirable products in the least possible time as well as optimum temperature, pressure, concentrations and quantity and quality of catalyst. ${ }^{25-32}$

\section{MATERIALS AND METHODS}

Sulfuric acid $98 \%$, acetone, Potassium permanganate, potassium iodide and sodium thiosulfate were purchased from Merck \& Co. To determine order of reaction based on Re. 1 and Eq. 1 , the concentration of each reactant was concerned much less than others. Reaction was carried out in $25^{\circ} \mathrm{C}$ and atmospheric pressure. Designated volumes of homogeneous solution were sampled at different times and the potassium permanganate concentration was detected with iodometric method and UV-Vis spectroscopy at $526 \mathrm{~nm}$ wavelength. The Fig. 1 shows UV-Vis spectrum of potassium permanganate solution using double distilled water and acetone. In chemistry, a calibration curve, also known as a standard curve, is a general method for determining the concentration of a substance in an unknown sample by comparing the unknown to a set of standard samples of known concentration. See Table 1 and refer to Figure 2.

Re.1: $5\left(\mathrm{CH}_{3}\right)_{2} \mathrm{CO}+6 \mathrm{KMnO}_{4}+9 \mathrm{H}_{2} \mathrm{SO}_{4} \rightarrow$ $3 \mathrm{~K}_{2} \mathrm{SO}_{4}+6 \mathrm{MnSO}_{4}+5 \mathrm{CH}_{3} \mathrm{COOH}+5 \mathrm{HCOOH}+9 \mathrm{H}_{2} \mathrm{O}$.

Eq.1: Rate $=\mathrm{k}\left[\mathrm{KMnO}_{4}\right]^{1}\left[\mathrm{H}_{2} \mathrm{SO}_{4}\right]^{1}\left[\left(\mathrm{CH}_{3}\right)_{2}\right.$ $\mathrm{CO}]^{1}\left[\mathrm{MnSO}_{4}\right]^{0}\left[\mathrm{CH}_{3} \mathrm{CHOOH}\right]^{0}[\mathrm{HCOOH}]^{0}$. 
To find a probable linear relationship between time and concentration, diagrams of [reactant], [reactant $]^{-1}$ and In[reactant] versus time and [product], [product $^{-1}$ and $\ln$ [product] versus time were plotted.

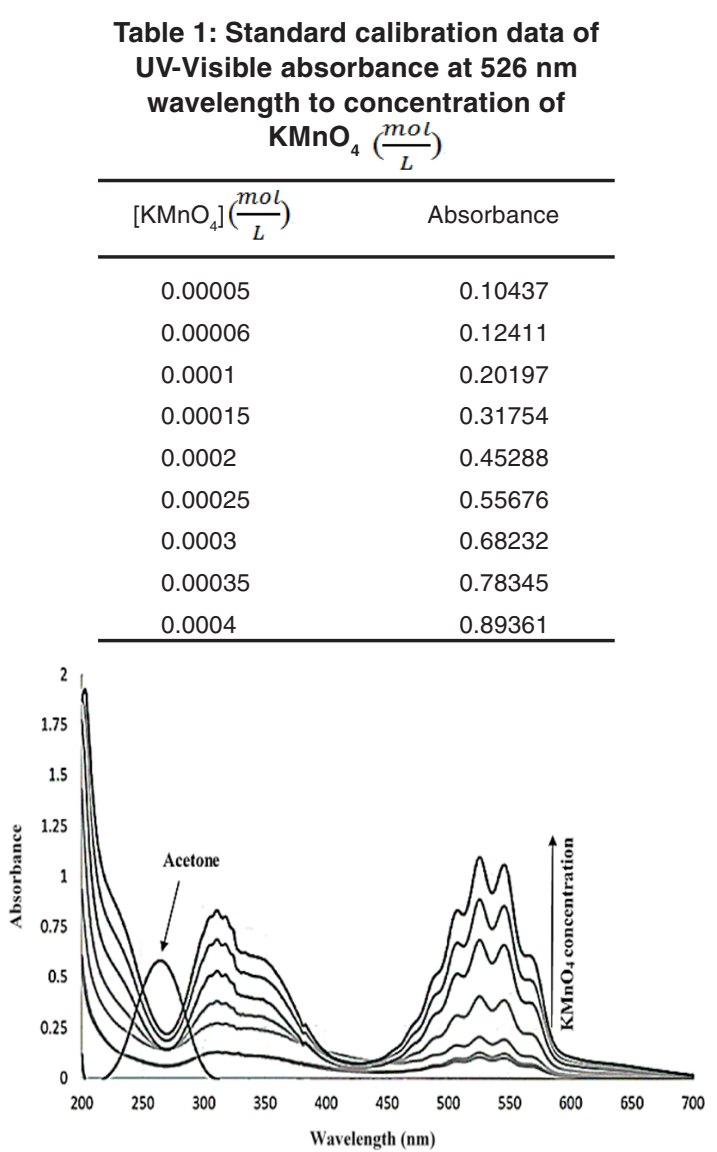

Fig. 1. Spectrum of potassium permanganate solution in the UV-Visible region. (Spectral band $(200-600 \mathrm{~nm})$ in the oxidation of acetone with permanganate ion in aqueous solutions.)

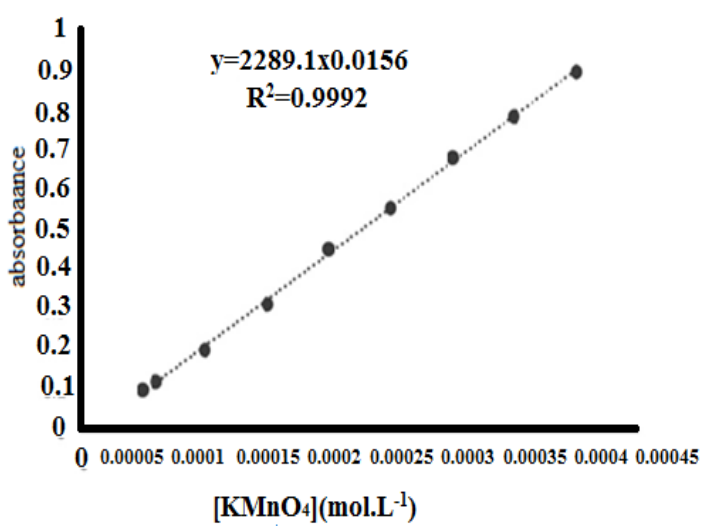

Figure 2: Standard calibration curve of UV-Visible absorbance at $526 \mathrm{~nm}$ wavelength to concentration of $\mathrm{KMnO}_{4}\left(\frac{\mathrm{mol}}{\mathrm{L}}\right)$
Table 2: $\mathrm{KMnO}_{4}$ concentration (mol. $\mathrm{L}^{-1}$ ) and at different times in reactions

\begin{tabular}{ccc}
\hline Time $(\mathrm{min})$ & {$[\mathrm{KMnO} 4]\left(\frac{\mathrm{mol}}{L}\right)$} & $-\operatorname{In}\left[\mathrm{KMnO}_{4}\right]$ \\
\hline 0 & 0.0047 & 5.36 \\
14 & 0.00446 & 5.426 \\
33 & 0.00427 & 5.456 \\
51 & 0.00407 & 5.504 \\
85 & 0.00379 & 5.575 \\
123 & 0.00355 & 5.64 \\
150 & 0.00335 & 5.698 \\
189 & 0.00308 & 5.782 \\
224 & 0.00288 & 5.85 \\
270 & 0.0026 & 5.952 \\
321 & 0.0023 & 6.074 \\
390 & 0.00189 & 6.27 \\
\hline
\end{tabular}

Table 3: Acetone concentration (mol.L-1) and-In[acetone] at different times in reactions

\begin{tabular}{ccc}
\hline Time $(\mathrm{min})$ & [acetone] $\left(\frac{\mathrm{mol}}{L}\right)$ & $-\operatorname{In}[$ acetone] \\
\hline 0 & 0.0268 & 3.62 \\
823 & 0.0262 & 3.64 \\
1675 & 0.0254 & 3.67 \\
2425 & 0.0252 & 3.68 \\
3113 & 0.0247 & 3.7 \\
3740 & 0.0243 & 3.717 \\
4428 & 0.024 & 3.73 \\
5223 & 0.0235 & 3.75 \\
5899 & 0.0231 & 3.765 \\
6349 & 0.023 & 3.77 \\
7219 & 0.0225 & 3.795 \\
\hline
\end{tabular}

\section{RESULTS}

Determining rate laws and the order of the reaction

In fact, stainless steel constant temperature bath at $25.0^{\circ} \mathrm{C}$ have been used for the following aqueous solutions and all experiments. It is important to make a distinction between order with respect to concentration and order with respect to time. The order with respect to concentration can be obtained from experiments in which initial rates are measured at a series of initial concentrations. The order with respect to time is determined from measurements of reactant concentration as a function of time of reaction. The order with respect to time will be the same as the order with respect to concentration if the reaction goes to completion and the rate is unaffected by products. To find the order of the reaction for potassium permanganate, a solution was prepared using acetone, Potassium permanganate and sulfuric acid with concentrations of $0.206,0.00486$ and $0.36 \mathrm{M}$, respectively. Data 
was collected and diagrams were plotted. As shown in Fig. 3a, there is a linear relationship between logarithm concentration of potassium permanganate and time. So, the obtained order of the reaction for potassium permanganate was ${ }^{1}$. To find the order of the reaction for acetone, a solution was prepared using acetone, potassium permanganate and sulfuric acid with concentrations of $0.0267,0.0101$ and $0.36 \mathrm{M}$, respectively. Data was collected and diagrams were plotted. As shown in Fig. 3b, there is a linear relationship between logarithm concentration of acetone and time. So, the obtained order of the reaction for acetone and potassium permanganate was the same. To determine the order of the reaction for sulfuric acid, 10 solutions with sulfuric acid, concentrations of $0.36,0.50,0.75,1.00,1.25$, $1.50,1.75,2.00,2.25$ and 2.50 molar together with constant concentrations of acetone and potassium permanganate were prepared. Data was collected and diagrams were plotted. See Table 4 and refer to Fig. 4. There was a linear relationship between concentration of sulfuric acid and reaction rate. So, the obtained order of the reaction for sulfuric acid was one. Fig. 4 shows diagrams related to the order of the reaction for sulfuric acid.

Table 4: The rate of reaction versus initial $\mathrm{H}_{2} \mathrm{SO}_{4}$ concentration for the first (A) 25, (B) 50, (C) 75 and (D) 100 minutes

\begin{tabular}{|c|c|c|c|c|}
\hline$\left[\mathrm{H}_{2} \mathrm{SO}_{4}\right]\left(\frac{\mathrm{mol}}{L}\right)$ & Rate $\left(\frac{\mathrm{A}}{\text { L.min }}\right) \times 10^{6}$ & Rate $\left(\frac{\mathrm{mol}}{\text { L.min }}\right) \times 10^{6}$ & Rate $\left(\frac{\text { mol }}{\text { L.min }}\right) \times 10^{6}$ & Rate $\left(\frac{\mathrm{mol}}{\boldsymbol{L} \cdot \boldsymbol{m i n}}\right) \times 10^{6}$ \\
\hline 0 & 0 & 0 & 0 & 0 \\
\hline 0.36 & 3.5 & 2.8 & 2.1 & 1.86 \\
\hline 0.50 & 4.98 & 3.5 & 2.78 & 2.4 \\
\hline 0.72 & 7.52 & 5.1 & 3.98 & 3.1 \\
\hline 1.00 & 9.3 & 6.5 & 4.99 & 3.9 \\
\hline 1.25 & 11.2 & 7.43 & 5.7 & 4.98 \\
\hline 1.50 & 14.3 & 8.9 & 7.03 & 5.85 \\
\hline 1.75 & 16.66 & 10.8 & 7.98 & 6.87 \\
\hline 2.00 & 18.4 & 12.1 & 9.2 & 7.86 \\
\hline 2.25 & 20.9 & 13.8 & 10.58 & 8.78 \\
\hline 2.50 & 23.8 & 14.8 & 11.8 & 9.93 \\
\hline
\end{tabular}

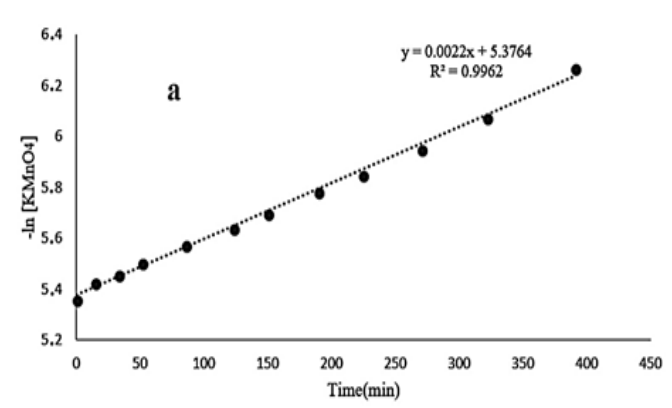

\section{Order of reaction for products}

It was observed that there is no relationship between products' concentration and rate of reaction. Solutions with constant concentrations of [Acetone] $=0.206 \mathrm{~mol} . \mathrm{L}^{-1},\left[\mathrm{KMnO}_{4}\right]=0.00350 \mathrm{~mol}$. $\mathrm{L}^{-1}$ and $\left[\mathrm{H}_{2} \mathrm{SO}_{4}\right]=1.00 \mathrm{~mol}$. $\mathrm{L}^{-1}$ and different $\mathrm{MnSO}_{4}$ concentrations were prepared as reaction medium. The potassium permanganate concentration was detected at the same reaction times and results were shown in Table 5. As shown in this table, there is no relationship between $\mathrm{MnSO}_{4}$ concentration and reaction rate. To find reaction rate dependence on $\mathrm{K}_{2} \mathrm{SO}_{4}$ concentration, similar experiment was designed and $\mathrm{KMnO}_{4}$ concentrations were evaluated at different reactions times. Data on Table 6 shows that there is no dependence between reaction rate and $\mathrm{K}_{2} \mathrm{SO}_{4}$ concentration. Solutions with constant concentrations of [Acetone] $=0.206 \mathrm{~mol}^{\mathrm{L}} \mathrm{L}^{-1},\left[\mathrm{KMnO}_{4}\right]$ $=0.00500 \mathrm{~mol} . \mathrm{L}^{-1}$ and $\left[\mathrm{H}_{2} \mathrm{SO}_{4}\right]=1.00 \mathrm{~mol} . \mathrm{L}^{-1}$ and different acetic acid concentrations were prepared as reaction medium. The $\mathrm{KMnO}_{4}$ concentration was detected at the same reaction times and results were 
shown in Table 7. The table suggests that there is no relationship between acetic acid concentration and reaction rate. To find reaction rate dependence on formic acid concentration, similar experiment was designed and $\mathrm{KMnO}_{4}$ concentrations were evaluated at different reactions times. Data on
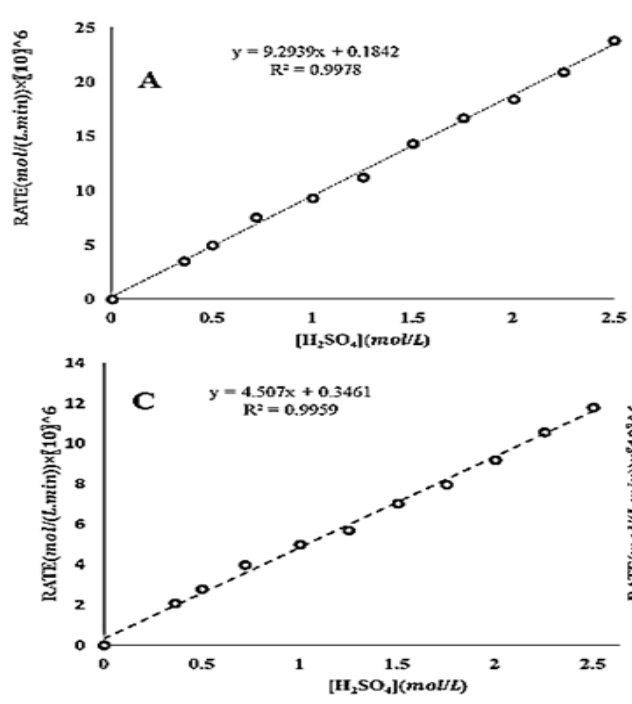

Table 8 shows that there is no dependence between reaction rate and formic acid concentration. In other words, the rate of the reaction do not vary with increasing nor decreasing products concentrations. Therefore, the reaction rate law is appeared as Eq. 1 Rate $=\mathrm{k}\left[\mathrm{KMnO}_{4}\right]\left[\mathrm{H}_{2} \mathrm{SO}_{4}\right]\left[\left(\mathrm{CH}_{3}\right)_{2} \mathrm{CO}\right]$
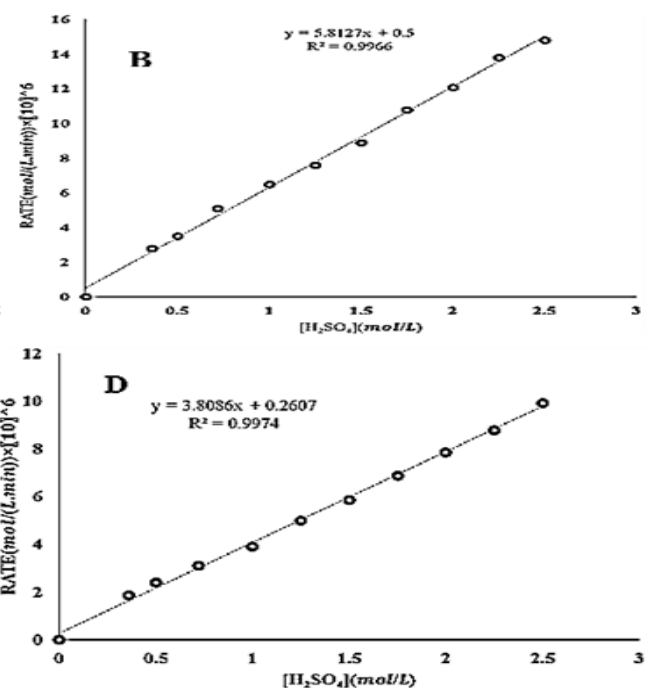

Fig. 4. The rate of reaction versus initial $\mathrm{H}_{2} \mathrm{SO}_{4}$ concentration for the first (A) 25, (B) 50, (C) 75 and (D) 100 minutes

Table 5: $\mathrm{KMnO}_{4}$ concentration $\left(\mathrm{mol}^{\left.-\mathrm{L}^{-1}\right)}\right.$ at different times in reactions with different initial concentrations of $\mathrm{MnSO}_{4}$

\begin{tabular}{|c|c|c|c|c|}
\hline Time (min) & {$\left[\mathrm{MnSO}_{4}\right] 0.00250 \mathrm{~mol}^{-\mathrm{L}^{-1}}$} & {$\left[\mathrm{MnSO}_{4}\right] 0.00500 \mathrm{~mol}^{-\mathrm{L}^{-1}}$} & {$\left[\mathrm{MnSO}_{4}\right] 0.01000 \mathrm{~mol}^{-\mathrm{L}^{-1}}$} & {$\left[\mathrm{MnSO}_{4}\right] 0.01500 \mathrm{~mol}^{-\mathrm{L}^{-1}}$} \\
\hline 10 & $3.300 \times 10^{-3}$ & $3.301 \times 10^{-3}$ & $3.301 \times 10^{-3}$ & $3.302 \times 10^{-3}$ \\
\hline 20 & $2.950 \times 10^{-3}$ & $2.950 \times 10^{-3}$ & $2.950 \times 10^{-3}$ & $2.950 \times 10^{-3}$ \\
\hline 30 & $2.801 \times 10^{-3}$ & $2.800 \times 10^{-3}$ & $2.802 \times 10^{-3}$ & $2.803 \times 10^{-3}$ \\
\hline 40 & $2.602 \times 10^{-3}$ & $2.602 \times 10^{-3}$ & $2.604 \times 10^{-3}$ & $2.601 \times 10^{-3}$ \\
\hline 50 & $2.581 \times 10^{-3}$ & $2.580 \times 10^{-3}$ & $2.580 \times 10^{-3}$ & $2.580 \times 10^{-3}$ \\
\hline 60 & $2.550 \times 10^{-3}$ & $2.550 \times 10^{-3}$ & $2.554 \times 10^{-3}$ & $2.553 \times 10^{-3}$ \\
\hline 70 & $2.463 \times 10^{-3}$ & $2.460 \times 10^{-3}$ & $2.465 \times 10^{-3}$ & $2.460 \times 10^{-3}$ \\
\hline 80 & 2. $410 \times 10^{-3}$ & 2. $411 \times 10^{-3}$ & 2. $411 \times 10^{-3}$ & 2. $410 \times 10^{-3}$ \\
\hline 90 & $2.380 \times 10^{-3}$ & $2.380 \times 10^{-3}$ & $2.380 \times 10^{-3}$ & $2.380 \times 10^{-3}$ \\
\hline 100 & $2.321 \times 10^{-3}$ & $2.320 \times 10^{-3}$ & $2.322 \times 10^{-3}$ & $2.323 \times 10^{-3}$ \\
\hline 110 & $2.240 \times 10^{-3}$ & $2.240 \times 10^{-3}$ & $2.241 \times 10^{-3}$ & $2.242 \times 10^{-3}$ \\
\hline 120 & $2.141 \times 10^{-3}$ & $2.140 \times 10^{-3}$ & $2.142 \times 10^{-3}$ & $2.140 \times 10^{-3}$ \\
\hline
\end{tabular}

Table 6: $\mathrm{KMnO}_{4}$ concentration $\left(\mathrm{mol}^{\left.-\mathrm{L}^{-1}\right)}\right.$ at different times in reactions with different initial concentrations of $\mathrm{K}_{2} \mathrm{SO}_{4}$

\begin{tabular}{ccccc}
\hline Time $(\mathrm{min})$ & {$\left[\mathrm{K}_{2} \mathrm{SO}_{4}\right]$ 0.00250 mol.L-1 } & {$\left[\mathrm{K}_{2} \mathrm{SO}_{4}\right] 0.00500 \mathrm{~mol} . \mathrm{L}^{-1}$} & {$\left[\mathrm{~K}_{2} \mathrm{SO}_{4}\right]$ 0.01000 mol.L-1 } & {$\left[\mathrm{K}_{2} \mathrm{SO}_{4}\right] 0.01500 \mathrm{~mol}^{-L^{-1}}$} \\
\hline 10 & $3.302 \times 10^{-3}$ & $3.301 \times 10^{-3}$ & $3.300 \times 10^{-3}$ & $3.301 \times 10^{-3}$ \\
20 & $2.950 \times 10^{-3}$ & $2.950 \times 10^{-3}$ & $2.950 \times 10^{-3}$ & $2.950 \times 10^{-3}$ \\
30 & $2.803 \times 10^{-3}$ & $2.800 \times 10^{-3}$ & $2.801 \times 10^{-3}$ & $2.802 \times 10^{-3}$ \\
40 & $2.601 \times 10^{-3}$ & $2.602 \times 10^{-3}$ & $2.602 \times 10^{-3}$ & $2.604 \times 10^{-3}$ \\
50 & $2.580 \times 10^{-3}$ & $2.580 \times 10^{-3}$ & $2.581 \times 10^{-3}$ & $2.580 \times 10^{-3}$ \\
60 & $2.553 \times 10^{-3}$ & $2.550 \times 10^{-3}$ & $2.550 \times 10^{-3}$ & $2.554 \times 10^{-3}$ \\
70 & $2.460 \times 10^{-3}$ & $2.460 \times 10^{-3}$ & $2.463 \times 10^{-3}$ & $2.465 \times 10^{-3}$ \\
80 & $2.410 \times 10^{-3}$ & $2.411 \times 10^{-3}$ & $2.410 \times 10^{-3}$ & $2.411 \times 10^{-3}$ \\
90 & $2.380 \times 10^{-3}$ & $2.380 \times 10^{-3}$ & $2.380 \times 10^{-3}$ & $2.380 \times 10^{-3}$ \\
100 & $2.323 \times 10^{-3}$ & $2.320 \times 10^{-3}$ & $2.321 \times 10^{-3}$ & $2.322 \times 10^{-3}$ \\
110 & $2.242 \times 10^{-3}$ & $2.240 \times 10^{-3}$ & $2.240 \times 10^{-3}$ & $2.241 \times 10^{-3}$ \\
120 & $2.140 \times 10^{-3}$ & $2.140 \times 10^{-3}$ & $2.141 \times 10^{-3}$ & $2.142 \times 10^{-3}$ \\
\hline
\end{tabular}


RASA et al., Orient. J. Chem., Vol. 35(1), 343-350 (2019)

Table 7: $\mathrm{KMnO}_{4}$ concentration $\left(\mathrm{mol}^{\left.\mathrm{L}-\mathrm{L}^{-1}\right)}\right.$ at different times in reactions with different initial concentrations of acetic acid Time (min) $\left[\mathrm{CH}_{3} \mathrm{COOH}\right] 0.0100 \mathrm{~mol} . \mathrm{L}^{-1} \quad\left[\mathrm{CH}_{3} \mathrm{COOH}\right] 0.0150 \mathrm{~mol} . \mathrm{L}^{-1} \quad\left[\mathrm{CH}_{3} \mathrm{COOH}\right] 0.0200 \mathrm{~mol} . \mathrm{L}^{-1} \quad\left[\mathrm{CH}_{3} \mathrm{COOH}\right] 0.0400 \mathrm{~mol} . \mathrm{L}^{-1}$

\begin{tabular}{rllll}
\hline 10 & $4.400 \times 10^{-3}$ & $4.400 \times 10^{-3}$ & $4.400 \times 10^{-3}$ & $4.400 \times 10^{-3}$ \\
20 & $3.840 \times 10^{-3}$ & $3.844 \times 10^{-3}$ & $3.842 \times 10^{-3}$ & $3.841 \times 10^{-3}$ \\
30 & $3.620 \times 10^{-3}$ & $3.622 \times 10^{-3}$ & $3.620 \times 10^{-3}$ & $3.623 \times 10^{-3}$ \\
40 & $3.384 \times 10^{-3}$ & $3.385 \times 10^{-3}$ & $3.386 \times 10^{-3}$ & $3.385 \times 10^{-3}$ \\
50 & $3.340 \times 10^{-3}$ & $3.341 \times 10^{-3}$ & $3.340 \times 10^{-3}$ & $3.343 \times 10^{-3}$ \\
60 & $3.162 \times 10^{-3}$ & $3.162 \times 10^{-3}$ & $3.161 \times 10^{-3}$ & $3.161 \times 10^{-3}$ \\
70 & $2.960 \times 10^{-3}$ & $2.961 \times 10^{-3}$ & $2.962 \times 10^{-3}$ & $2.961 \times 10^{-3}$ \\
80 & $2.800 \times 10^{-3}$ & $2.800 \times 10^{-3}$ & $2.800 \times 10^{-3}$ & $2.800 \times 10^{-3}$ \\
90 & $2.721 \times 10^{-3}$ & $2.720 \times 10^{-3}$ & $2.719 \times 10^{-3}$ & $2.720 \times 10^{-3}$ \\
100 & $2.480 \times 10^{-3}$ & $2.480 \times 10^{-3}$ & $2.480 \times 10^{-3}$ & $2.480 \times 10^{-3}$ \\
110 & $2.400 \times 10^{-3}$ & $2.400 \times 10^{-3}$ & $2.400 \times 10^{-3}$ & $2.400 \times 10^{-3}$ \\
120 & $2.311 \times 10^{-3}$ & $2.312 \times 10^{-3}$ & $2.310 \times 10^{-3}$ & $2.311 \times 10^{-3}$ \\
\hline
\end{tabular}

Table 8: $\mathrm{KMnO}_{4}$ concentration $\left(\mathrm{mol}^{-\mathrm{L}^{-1}}\right)$ at different times in reactions with different initial concentrations of formic acid

\begin{tabular}{rcccc}
\hline Time $(\mathrm{min})$ & {$[\mathrm{HCOOH}] \mathrm{O} .0100 \mathrm{~mol}^{-L^{-1}}$} & {$[\mathrm{HCOOH}] 0.0150 \mathrm{~mol} . \mathrm{L}^{-1}$} & {$[\mathrm{HCOOH}] 0.0200 \mathrm{~mol}^{-1}$} & {$[\mathrm{HCOOH}] 0.0400 \mathrm{~mol} . \mathrm{L}^{-1}$} \\
\hline 10 & $4.400 \times 10^{-3}$ & $4.400 \times 10^{-3}$ & $4.400 \times 10^{-3}$ & $4.400 \times 10^{-3}$ \\
20 & $3.844 \times 10^{-3}$ & $3.841 \times 10^{-3}$ & $3.840 \times 10^{-3}$ & $3.842 \times 10^{-3}$ \\
30 & $3.622 \times 10^{-3}$ & $3.623 \times 10^{-3}$ & $3.620 \times 10^{-3}$ & $3.620 \times 10^{-3}$ \\
40 & $3.385 \times 10^{-3}$ & $3.385 \times 10^{-3}$ & $3.384 \times 10^{-3}$ & $3.386 \times 10^{-3}$ \\
50 & $3.341 \times 10^{-3}$ & $3.343 \times 10^{-3}$ & $3.340 \times 10^{-3}$ & $3.340 \times 10^{-3}$ \\
60 & $3.162 \times 10^{-3}$ & $3.161 \times 10^{-3}$ & $3.162 \times 10^{-3}$ & $3.161 \times 10^{-3}$ \\
70 & $2.961 \times 10^{-3}$ & $2.961 \times 10^{-3}$ & $2.960 \times 10^{-3}$ & $2.962 \times 10^{-3}$ \\
80 & $2.800 \times 10^{-3}$ & $2.800 \times 10^{-3}$ & $2.800 \times 10^{-3}$ & $2.800 \times 10^{-3}$ \\
90 & $2.720 \times 10^{-3}$ & $2.720 \times 10^{-3}$ & $2.721 \times 10^{-3}$ & $2.719 \times 10^{-3}$ \\
100 & $2.480 \times 10^{-3}$ & $2.480 \times 10^{-3}$ & $2.480 \times 10^{-3}$ & $2.480 \times 10^{-3}$ \\
110 & $2.400 \times 10^{-3}$ & $2.400 \times 10^{-3}$ & $2.400 \times 10^{-3}$ & $2.400 \times 10^{-3}$ \\
120 & $2.312 \times 10^{-3}$ & $2.311 \times 10^{-3}$ & $2.311 \times 10^{-3}$ & $2.310 \times 10^{-3}$ \\
\hline
\end{tabular}

\section{DISCUSSION}

It has been established that in acidic medium the stable reduction product of potassium permanganate is $\mathrm{Mn}^{2+}$ ion. Therefore, the below mechanism was proposed based on the kinetic results and spectral analyses carried out. Based upon the above results a suitable mechanism for the oxidation of acetone can be suggested as follows. The permanganic acid react with enol form of acetone to form complex A. This complex finally gives Acetic acid and formaldehyde. We propose the simplified mechanism below for the oxidation of acetone by potassium permanganate in acidic medium.

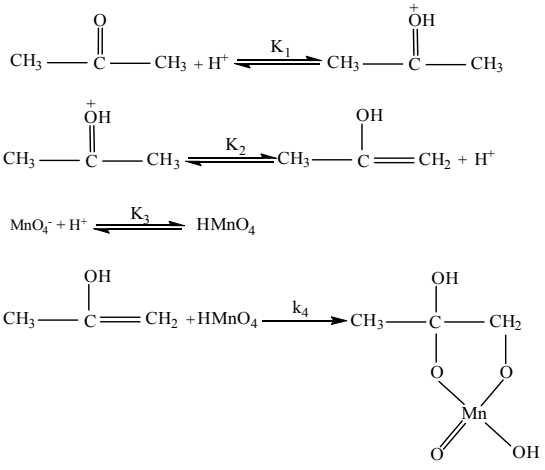

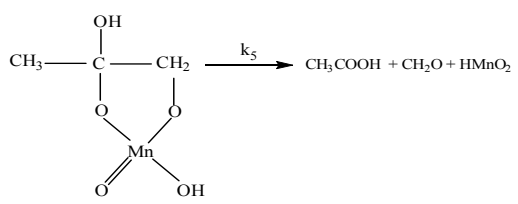<smiles>O=CC#CC=CC=O</smiles><smiles>[1H]C(O)(NCCCCC)OS(=O)(=O)O</smiles>

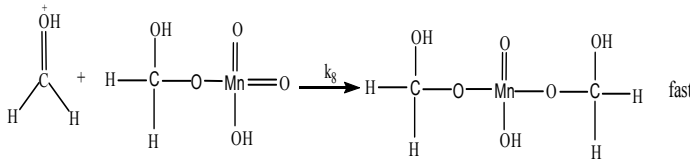

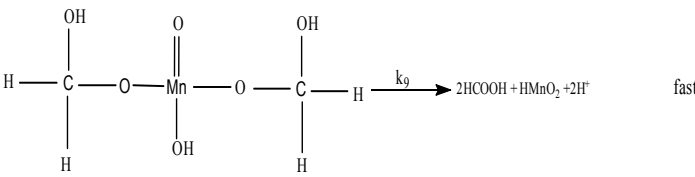

$\mathrm{HCHO}+2 \mathrm{HMnO}_{2}+4 \mathrm{H}^{+} \stackrel{\mathrm{k}_{10}}{\longrightarrow} \mathrm{HCOOH}+2 \mathrm{Mn}^{+2}+3 \mathrm{H}_{2} \mathrm{O}$

fast 
A suitable rate expression in consistent with above observation can be formulated as follows:

$$
\begin{aligned}
& \text { Rate }=\mathrm{k}_{4}\left[\mathrm{CH}_{3} \stackrel{\stackrel{\mathrm{OH}}{\mathrm{C}}=\mathrm{CH}_{3}}{=}\right]\left[\mathrm{HMnO}_{4}\right] \\
& \mathrm{K}_{1}=\frac{\left[\mathrm{CH}_{3}-\stackrel{\stackrel{+}{\mathrm{O}} \mathrm{H}}{\mathrm{C}}-\mathrm{CH}_{3}\right]}{\left[\mathrm{CH}_{3}-\stackrel{\mathrm{O}}{\mathrm{C}}-\mathrm{CH}_{3}\right]\left[\mathrm{H}^{+}\right]} \\
& \mathrm{K}_{2}=\frac{\left[\mathrm{CH}_{3}-\stackrel{\mathrm{OH}}{\mathrm{C}}=\mathrm{CH}_{2}\right]\left[\mathrm{H}^{+}\right]}{\left[\mathrm{CH}_{3}-\stackrel{\stackrel{\mathrm{O}}{\mathrm{C}}-\mathrm{CH}_{3}}{=}\right.} \\
& \mathrm{K}_{3}=\frac{\left[\mathrm{HMnO}_{4}\right]}{\left[\mathrm{MnO}_{4}^{-}\right]\left[\mathrm{H}^{+}\right]} \quad\left[\mathrm{HMnO}_{4}\right]=\mathrm{K}_{3} \quad\left[\mathrm{MnO}_{4}^{-}\right]\left[\mathrm{H}^{+}\right] \\
& {\left[\mathrm{CH}_{3} \stackrel{\stackrel{+}{\mathrm{O}} \mathrm{H}}{\mathrm{C}}-\mathrm{CH}_{3}\right]=\mathrm{K}_{1}\left[\mathrm{CH}_{3} \stackrel{\mathrm{O}}{\mathrm{C}}-\mathrm{CH}_{3}\right]\left[\mathrm{H}^{+}\right]} \\
& {\left[\mathrm{CH}_{3}-\stackrel{\mathrm{OH}}{\mathrm{C}}=\mathrm{CH}_{2}\right]=\frac{\mathrm{K}_{1} \mathrm{~K}_{2}\left[\mathrm{CH}_{3}-\stackrel{\mathrm{O}}{\mathrm{C}}-\mathrm{CH}_{3}\right]\left[\mathrm{H}^{+}\right]}{\left[\mathrm{H}^{+}\right]}=\mathrm{K}_{1} \mathrm{~K}_{2}\left[\mathrm{CH}_{3}-\stackrel{\mathrm{C}}{\mathrm{O}}-\mathrm{CH}_{3}\right]} \\
& \text { Rate }=\mathrm{k}_{4}\left[\mathrm{CH}_{3} \stackrel{\mathrm{OH}}{\mathrm{C}}=\mathrm{CH}_{3}\right]\left[\mathrm{HMnO}_{4}\right]=\mathrm{K}_{1} \mathrm{~K}_{2} \mathrm{~K}_{3} \mathrm{k}_{4}\left[\mathrm{CH}_{3}-\stackrel{\mathrm{O}}{\mathrm{C}}-\mathrm{CH}_{3}\right]\left[\mathrm{MnO}_{4}^{-}\right]\left[\mathrm{H}^{+}\right] \\
& \mathrm{k}=\mathrm{K}_{1} \mathrm{~K}_{2} \mathrm{~K}_{3} \mathrm{k}_{4} \\
& \text { Rate }=\mathrm{k}\left[\mathrm{CH}_{3} \stackrel{\mathrm{O}}{\mathrm{C}}-\mathrm{CH}_{3}\right]\left[\mathrm{MnO}_{4}^{-}\right]\left[\mathrm{H}^{+}\right]
\end{aligned}
$$

\section{CONCLUSION}

Kinetics of acetone oxidation were investigated in an aqueous solution of potassium permanganate in sulfuric acid environment. The findings indicated reaction order of 1 for acetone and potassium permanganate and sulfuric acid, so the reaction rate law was determined as: Rate = $\mathrm{k}\left[\left(\mathrm{CH}_{3}\right)_{2} \mathrm{CO}\right]$. $\left[\mathrm{KMnO}_{4}\right] \cdot\left[\mathrm{H}_{2} \mathrm{SO}_{4}\right]$. The reaction rate law suggests a complicated reaction mechanism that occurs even in lower acetone concentrations. Moreover, increasing temperature and reactants concentrations are necessary for a fast acetone oxidation. A reaction mechanism in good consistent with the kinetic results was suggested and discussed.

\section{ACKNOWLEDGEMENT}

This work was financially supported by a research grant from University of Kashan.

\section{REFERENCE}

1. Klaassen, C. D. Casarett and Doull's 2013 In Toxicology: The Basic Science of Poisons, $8^{\text {th }}$ edn. McGraw-Hill Publishing Co., Inc., New York., 2013, 866-916, 1123-1140.

2. Atlanta, G. A. ATSDR., 1994, 1-86.

3. Haggard, H. W.; Greenberg, L.A.; Turner, J.M. J. Ind. Hygiene Toxicol., 1994, 26, 133-151.

4. Forsyth, C. U.S. EPA, Office of Solid Waste and Emergency Response., 2003, 22-32.

5. Baltroke, I. M.; Sadeghi, M. M.; Mahmoodi, N.; Kharesh, B. Indian J. Chem., 1997, 36, 438.

6. Dinesh, P.; Dilsha, K. M.; Seema, K. J. Indian Chem Soc., 2006, 86, 816.

7. Dilsha, K. M.; Kothari, S. Prog. Reac. Kinet. Meach., 2007, 32, 119.

8. Kothari, S. Goyal, A., Banerji, K. K. J. Chem. Res., 2002, 363, 863-878. 
9. Seema, K.; Kathari, A.; Banerji, K. K. Indian J. Chem., 2000, 39, 734.

10. Abdul aziz, saeed.; Awn, N.; Farooqui, M. Int. J. Chem. Sci., 2013, 11, 1401-1406.

11. Likhodii, S.S.; Serbanescu, I.; Cortez, M.A.; Murphy, P.; Snead, O. C.; Burnham, W. M. Ann Neurol., 2003, 54, 219-226.

12. Spivey, J.J.; Webb, G. Complete Oxidation of Volatile Organics, Catalysis. The Royal Society of Chemistry, Cambridge., 1989, 26, 2165-2180.

13. Prasad, R.; Kennedy, L. A.; Ruckenstein, E. Catal. Rev. Sci. Eng., 1984, 26, 1-58.

14. Zwinkels, M. F. M.; Järås, S. G.; Menon, P. G.; Griffin, T. A. Catal. Rev. Sci. Eng., 1993, 35, 319.

15. Noordally, E.; Richmond, J. R.; Tahir, S. F. Catal, Today., 2003, 17, 359.

16. Manivannan, G.; Maruthamuthu, P. J. Chem. Soc, Perkin Trans 2., 1986, 4, 565.

17. Latona, D. F. Carib. J. Sci Tech., 2016, 4, 939-947.

18. Radhakrisnamurti, P.S.; Rao, M. D. P. Indian J. Chem. Sect. A., 1977, 15, 524.

19. Nath, P.; Banerji, K. K. Indian J. Chem. Sect. A., 1976, 14, 660.

20. Nath, M. P; Banerji, K. K. Aust. J. Chem., 1976, 29, 1939.
21. Sen, P. K.; Mukhopadhyay, G.K.; Sen Gupta, K. Transition Met. Chem., 1998, 23, 577.

22. Wiberg, K. B.; Geer, R. D. J. Am. Chem. Soc., 1965, 87, 5202.

23. Lee, D. G. APA. The Oxidation of Organic Compounds by Permanganate lon and hexavalent Chromium. Open Court: La Salle., 1980,

24. Ja'ky, M.; Szammer, J.; Simon-Trompler, E. J. Chem. Soc. Perkin Trans., 2000, 2, 1597-1602.

25. Freeman, F.; Chang, L.Y.; Sumarta, L. J. Org. Chem., 1987, 52, 1460.

26. Carrington, A.; Symons, M. C. R. Cem. Rev., 1963, 63, 443-460.

27. Freeman, F. React. Species Chem. React., 1976, 1, 179-226.

28. Cotton, F.A.; Wilkinson, G. Advanced Inorganic Chemistry, John Wiley and Sons., 1980, 738- 748.

29. Dash, S.; Patel, S.; Mishra, B. K. Tetrahedron., 2009, 65, 707-739.

30. Hussain, S. Orient. J. Chem., 2011, 27, 1729-1734.

31. Seema, K. Banerji, K. K. Oxidn. Commun., 2003, 23, 93.

32. Levine In Physical Chemistry, Sixth Edn. New York., 2009, 515-579. 